\title{
Os think tanks liberais no País A Universidade Aberta de Porto Alegre
}

\author{
Liane Maria Bernardi* \\ FABIOLA BOROWSKY \\ Monique Montano \\ Maria OTília Susin
}

\begin{abstract}
RESUMO: Este artigo trata da expansão dos think tanks no Brasil como estratégia de setores da política e da economia para divulgação e formação de opinião. A partir de fontes bibliográficas e de pesquisa documental, investigam-se o conteúdo da proposta, os sujeitos e a rede de apoiadores que cercam os think tanks, defensores das teorias liberais do capital humano e do empreendedorismo. A discussão se materializa na criação da Universidade Aberta de Porto Alegre.
\end{abstract}

Palavras-chave:Think tank. Liberalismo. Parcerias público-privadas. Universidade Aberta de Porto Alegre.

\section{The Country's liberal Think Tanks The Open University of Porto Alegre}

\begin{abstract}
This article deals with the expansion of think tanks in Brazil as a strategy of s political and economic sectors to disseminate
\end{abstract}

* Doutora em Educação pela Universidade Federal do Rio Grande do Sul. É professora aposentada do ensino fundamental da Prefeitura Municipal de Porto Alegre. É pesquisadora do Grupo de Pesquisa Relações entre o Público e o Privado na Educação- GPRPPE- da UFRGS. Porto Alegre, RS- Brasil. E-mail: $<$ lianebernardi@gmail.com>.

* É doutora em Educação pela Universidade Federal do Rio Grande do Sul e mestre em Educação pela Universidade Federal de Santa Catarina. Atualmente é professora da Prefeitura Municipal de Porto Alegre. Porto Alegre, RS- Brasil. E-mail: <fabiolaborowsky@yahoo.com.br>.

** É graduada em Pedagogia pela Universidade Federal do Rio Grande do Sul. Atualmente é professora pela Secretaria Municipal de Educação de Porto Alegre, atuando no Conselho Municipal Educação. Porto Alegre, RS- Brasil. E-mail: <moniquerobain@gmail.com>.

*** É mestre e doutora em Educação pela Universidade Federal do Rio Grande do Sul. É professora aposentada da Secretaria Municipal de Educação de Porto Alegre. Atualmente trabalha em Pesquisas da Universidade Federal do Rio Grande do Sul. Porto Alegre, RS- Brasil. E-mail: <otiliasusin@gmail.com>. 
and form opinion. Using bibliographical sources and documentary research, we investigate the content proposals, the subjects and the network of supporters who surround the thinktanks, defenders of liberal theories of human capital and entrepreneurship. The discussion materializes with the creation of the Open University of Porto Alegre.

Keywords:Think tank. Liberalism. Public-private partnerships. The Open University of Porto Alegre.

\section{Los think tanks liberales en Brasil}

La Universidade Aberta de Porto Alegre

RESUMEN: Este artículo analiza la expansión de los think tanks en Brasil como estrategia de sectores de la política y de la economía para divulgación y formación de opinión. A partir de fuentes bibliográficas y una cata documental, se investigan el contenido de la propuesta, los sujetos y la red de apoyo alrededor de los think tanks, defensores de las teorías liberales del capital humano y del emprendimiento. La discusión se materializa en la creación de la Universidade Aberta de Porto Alegre.

Palabras clave: Think tank. Liberalismo. Alianzas público-privadas. Universidade Aberta de Porto Alegre.

\section{Les think tanks libéraux dans le pays}

\section{L'Université Ouverte de Porto Alegre}

RÉSUMÉ: Cet article traite de l'expansion des think tanks au Brésil comme stratégie de secteurs de la politique et de l'économie pour la divulgation et la formation d'opinion. En se basant sur des sources bibliographiques et des recherches documentaires, le contenu de la proposition a été étudiée, tout comme les sujets et le réseau de partisans qui entourent les think tanks, défenseurs des théories libérales du capital humain et de l'entrepreneuriat. La discussion se matérialise avec la création de l’Université Ouverte de Porto Alegre.

Mots-clés: Think tank. Libéralisme. Partenariats public-privés. Université Ouverte de Porto Alegre. 


\section{Introdução}

$\mathrm{E}$ ste artigo é parte da pesquisa “Implicações da relação público-privada para a democratização da educação na América Latina: Uruguai, Argentina, Venezuela, Chile, Bolívia e Brasil", realizada pelo Grupo de Pesquisa Relações entre o Público e o Privado na Educação (GPRPPE), junto ao Programa de Pós-Graduação em Educação da Universidade Federal do Rio Grande do Sul.

Neste recorte, apresentamos discussões sobre a expansão no País de organizações conhecidas como think tanks ou advocacy think tanks (ROCHA, 2015), usadas para ativar o clima político de influência na opinião pública. No Brasil, a proliferação dessas instituições está associada ao projeto societário em disputa e são propulsoras de discussão sobre as velhas fórmulas liberais repaginadas e apresentadas como a nova estratégia cujo foco é o livre mercado.

A partir da discussão de teóricos sobre think tanks e da metodologia de análise documental em websites (como o da Prefeitura de Porto Alegre/RS, os decretos governamentais e os jornais locais), apresentaremos como exemplo desse movimento a criação da Universidade Aberta de Porto Alegre (UnA) que traz em sua base teórica o pensamento liberal da Escola de Chicago. ${ }^{1}$

A Escola de Chicago ficou conhecida nos anos de 1950 por ter realizado o transplante ideológico do neoliberalismo para outros países, incluindo os da América Latina ${ }^{2}$ e por celebrizar-se com a teoria do capital humano, adotada pelos organismos multilaterais no campo educacional, a partir dos anos de 1980. Destacamos que o conceito de capital humano (conhecimentos, competências que favoreçam o trabalho) está vinculado ao pensamento neoliberal no contexto das demandas resultantes da reestruturação produtiva do capitalismo.

De maneira geral, as estratégias do neoliberalismo acentuaram duas grandes exigências: "privatizar empresas estatais e serviços públicos" (MORAES, 2001, p.35), transferindo para a iniciativa privada as atividades sociais como educação, saúde, previdência e "diminuir a interferência dos poderes públicos sobre os empreendimentos privados" (Ibidem). Vera Peroni (2005) interpretou esse movimento como uma tentativa de redefinir o papel do Estado, ficando mínimo para as políticas sociais e máximo para o capital.

Nessa visão, o mercado é o espaço onde os indivíduos se movem, numa combinação de empreendedorismo e concorrência individual, estabelecendo um novo contrato social que vincula direitos a responsabilidades (GIDDENS, 2001). A partir desse mundo supostamente sem inimigos ou classes,

[...] a sociedade civil (onde cabem todos) deve ser incentivada a assumir as políticas sociais, e o Estado passa a ser o financiador ou aquele que deve proporcionar outros recursos para que as iniciativas sejam executadas. O papel assumido é o do empreendedorismo e da parceria entre sociedade civil e governo (BERNARDI, 2016, p. 54). 
Ou seja, os sujeitos são responsáveis "pelos destinos da sociedade, mas não qualquer sociedade, uma vez que prega o empreendedorismo e a concepção de mercado no conteúdo da política" (PERONI, 2015, p. 37). Esse tom individualista "demarca perdas para a possibilidade de um projeto de sociedade com justiça social, pois cada cidadão procura seu caminho. Se falhar, a culpa é sua e não do capitalismo" (BERNARDI, 2016, p. 58).

Sobre o mérito e sua subjetividade, Elaine Rossetti Behring (2008) contribuiu com a discussão sobre a busca do sucesso particular e a desagregação dos princípios de igualdade para todos, ao analisar a perspectiva da condução da reestruturação produtiva:

[...] em combinação com o ajuste neoliberal, o qual implica a desregulamentação de direitos, no corte de gastos sociais, em deixar milhões de pessoas a sua própria sorte e 'mérito' individuais- elemento que também desconstrói identidades, jogando indivíduos numa aleatória e violenta luta pela sobrevivência. Assinala-se, então, que o caráter da organização do trabalho é desagregador da solidariedade de classe e regressivo (BEHRING, 2008, p. 37).

Retomando a lógica neoliberal, Anthony Giddens (2001) faz a defesa do conceito de capacidade social (usar o acesso aos bens e não necessariamente a igualdade de todos, frente a eles) e o de meritocracia (alguns por sua capacidade vão merecer o bem).

Pierre Dardot e Christian Laval (2016, p.9), ao analisar esse processo individualista, alertam sobre as mutações na subjetividade provocadas pelo neoliberalismo que "operam no sentido do egoísmo social, da negação da solidariedade e da redistribuição que podem desembocar em movimentos reacionários ou até mesmo neofascistas".

Esses argumentos demarcam o referencial liberal que fundamenta os think tanks e a uma, explicitando a disputa com o projeto de sociedade democrática, participativa e com igualdade para todos.

A sustentação teórica do estudo está nos argumentos de Reginaldo Moraes (2001, 2015), Pierre Dardot e Christian Laval (2016), Camila Rocha (2015), Elaine Rosseti Behring (2003) e Vera Peroni (2005; 2015).

O artigo está organizado em três seções: (i) Breve histórico dos think tanks, em que definimos essa organização, apresentamos o histórico da sua constituição no País e apontamos as relações com organizações internacionais liberais. (ii) Proposta de parceria e think tank em Porto Alegre, a partir de documentos oficiais do Governo Municipal, com ênfase na educação. (iii) Universidade Aberta de Porto Alegre, em que exibimos o conteúdo da proposta, a rede de parceiros e suas interlocuções. (iv) Considerações finais, com a apresentação das conclusões sobre a criação da Universidade Aberta Porto Alegre como exemplo de think tank para realizar marketing político e preparação de terreno para mudanças liberais voltadas ao empreendedorismo e ao mercado. 


\section{Breve histórico dos think tanks no Brasil}

Nessa sessão apresentamos algumas discussões sobre as organizações ou instituições que atuam para grupos de interesse, produzindo e difundindo conhecimento sobre assuntos estratégicos com vistas às transformações sociais, políticas ou econômicas conhecidas pelo nome de think tanks. Observando sua origem, podemos afirmar que essas instituições podem ser independentes, sendo que a maioria é filiada a partidos políticos, governos ou corporações empresariais.

Os think tanks são "organizações permanentes de pesquisa e análise de políticas públicas que atuam a partir da sociedade civil, procurando informar e influenciar tanto instâncias governamentais como a opinião pública no que tange a adoção de determinadas políticas públicas" (ROCHA, 2015, p. 262).

Segundo Camila Rocha (2015, p. 262), a ação dos think thanks é pautada por sua localização em um espectro que vai do "profissionalismo politicamente desinteressado", de um lado, ao "ativismo político orientado ideologicamente", de outro, o que altera substancialmente as estratégias de persuasão e de convencimento adotadas por elas para influenciar o processo político de formulação e implementação de políticas públicas.

Os primeiros think tanks foram criados pelos norte-americanos na primeira metade do século XX; eram organizações civis privadas que reuniam especialistas e técnicos, normalmente recrutados junto à academia, dedicavam-se às pesquisas científicas e à divulgação de ideias no campo das políticas públicas; afirmavam conduzir suas atividades de forma "neutra", "científica", "desinteressada" e, por isso, mais "confiável" (ROCHA, 2015).

Apesar do discurso da neutralidade, o histórico de um dos think tanks de direita (mais influente dentro e fora dos EUA), o Heritage Fundation (criado em 1973), derruba este argumento ao afirmar que "sua missão é formular e promover políticas públicas conservadoras baseadas nos princípios da livre empresa, do estado mínimo, da liberdade individual, dos valores tradicionais norte-americanos e de uma forte defesa nacional" (ROCHA, 2015, p. 264). Esta instituição dirigia-se ao poder público e era conhecida como "think tank ativista"; seu objetivo era influenciar o clima político com análises de conjuntura, marketing e formação de opinião pública em defesa do livre mercado.

Os think tanks americanos atuavam fortemente engajados na defesa da diminuição do Estado na economia desde os anos de 1960 (ROCHA, 2015), mas, a partir dos anos de 1980, com a aplicação de políticas econômicas ortodoxas neoliberais nos EUA (Ronald Reagan) e Inglaterra (Margareth Thatcher), passam a ser estratégicas para a difusão de tais políticas em outros países. Muitos intelectuais, inspirados pela obra de Friedrich Hayek ${ }^{3}$ (ex-aluno do mago liberal Ludwig Von Mises), realizam trocas e fortalecem ideias neoliberais como os ativistas e as instituições criadas por eles para "remodelar a opinião pública" (MORAES, 2015, p.238).

Segundo Reginaldo Moraes, "Os think tanks se tornaram elementos centrais de fazer política" (Idem, p. 240), radicalizando o papel a que se propunham nos anos de 1960 e 1970 de defesa do livre mercado; criam cenários para enquadrar e moldar o ambiente político, 
"decidindo do que se trata o jogo e quem entra no jogo" (Idem, p. 233) e assim "o povo sabe o que lhe é permitido saber" (Ibidem). Outro elemento apontado como central neste cenário de modelagem de opinião é a destruição de conceitos progressistas, não apenas promovendo candidatos ou programas liberais, mas destruindo a reputação de pessoas, partidos ou bandeiras que defendem políticas sociais universais e estatais.

Além do Heritage Foundation, que se destaca pelo maior orçamento entre as instituições americanas, enfatizamos o Atlas Foundation, criado em Washington em 1981. Camila Rocha (2015, p. 269) afirma que "atualmente é possível dizer que todos os think tanks de direita mais importantes ao redor do globo fazem parte da rede constituída pelo Atlas". Nesse cenário, destacamos o Cato Institute como outra instituição atuante no Brasil.

Reginaldo Moraes (2015, p. 244) publicou o quadro que reproduzimos abaixo sobre as vinte instituições de direita mais conservadoras da virada do milênio e seus orçamentos:

\section{Quadro 1 - Orçamento dos vinte maiores think tanks (US\$ milhões/1996)}

\begin{tabular}{l|c}
\hline Heritage Foundation & 28,7 \\
\hline Hoover Institution & 19,5 \\
\hline Center for Strategic International Studies & 14,0 \\
\hline American Enterprise Institute & 13,0 \\
\hline Free Congress Research and Education & 11,5 \\
\hline Foundation Family Research Council & 10,2 \\
\hline Citizens for a Sound Economy & 10,0 \\
\hline Cato Institute & 8,0 \\
\hline Hudson Institute & 6,5 \\
\hline American Legislative Exchange Council & 5,0 \\
\hline Progress and Freedom Foundation & 5,0 \\
\hline Manhattan Institute & 5,0 \\
\hline National Center for Public Research & 4,0 \\
\hline Reason Foundation & 4,0 \\
\hline Empower America & 3,8 \\
\hline National Center for Policy Analysis & 3,2 \\
\hline Competitive Enterprise Institute & 2,5 \\
\hline Atlas Economic Research Foundation & $2,3(* 94)$ \\
\hline Ethics and Public Policy Center & 1,1 \\
\hline Employment Policy Foundation & $0,8(* 94)$ \\
\hline
\end{tabular}

Fonte: NCRP -National Committee four Responsivi Philanthropy (grifos das autoras). 
Apesar dos dados serem dos anos de 1990, o quadro já mostrava o poder político e econômico que estes institutos têm no cenário internacional. Segundo dados atualizados de Marina Amaral (2015, p.6), “a receita do Atlas ${ }^{4}$ em 2013 foi de US\$ 11,459 milhões”, demonstrando o empoderamento da instituição. Além disso, financiam cátedras, revistas e eventos em universidades, como por exemplo, a Universidade de Chicago (MORAES, 2015), buscando legitimação da sua ação. Esses think tanks também influenciaram a criação e manutenção de instituições similares na América Latina, com apoio material, treinamento de pessoal e intercâmbio de ideias e expertise.

Camila Rocha (2015) afirmou que os think tanks nos países latino-americanos tiveram momentos distintos de criação: $\mathrm{O}$ primeiro ocorre no contexto de instabilidade econômica e redemocratização após longas ditaduras, entre os anos de 1980 e 1990 quando se instalaram "novas associações civis e think tanks que alegavam defender o livre mercado" (p. 270), associando empresários locais e estrangeiros, como no exemplo do Brasil que criou o Instituto Liberal em 1983 e o Instituto de Estudos Empresariais em 1984. “O Atlas foi fundamental para conferir certo grau de homogeneidade aos discursos e práticas dos think tanks latino-americanos" (Idem, p.272) e introduzir as reformas liberais nos países como solução para a crise. O segundo momento se deu a partir dos anos 2000 quando na América Latina foram eleitos candidatos de esquerda que se apresentaram como alternativa aos grupos neoliberais, como Hugo Chaves na Venezuela, Nestor Kirchner na Argentina, Luís Inácio Lula da Silva no Brasil. Em resposta a esse processo, a nova onda de formação da direita na América Latina investiu fortemente na região, aportando recursos humanos e financeiros às instituições existentes e ampliando a formação de novas instituições.

Neste segundo momento de criação de think tanks, usamos novamente o Brasil como exemplo, pois "ao final do primeiro mandato do governo Lula surgiram várias organizações como o Instituto Millenium, O Instituto Ordem Livre, o Movimento Brasil Livre-MBL, etc." (ROCHA, 2015, p.275), conectados com as instituições já existentes.

Retomando a construção da hegemonia pelos think tanks, destacamos a atuação do Atlas Foundation enquanto financiador de uma organização estudantil chamada Students for Liberty que, por sua vez, tem se expandido em vários países e no Brasil deu origem ao Movimento Brasil Livre. Kim Kataguiri, um dos líderes do movimento, em entrevista à rede Globo afirmou a necessidade do MBL sair das ruas e se filiar a partidos políticos, cuja cartilha é a "redução do Estado na economia e na vida da população". 5

O crescimento dessas instituições na América Latina e, em especial, no Brasil, coloca em cena sujeitos que irão disputar a construção do consenso. Num contexto de menos ideias novas e mais novos modos de difundir ideias (MORAES, 2015), os think tanks têm se multiplicado para direcionar a política. Em Porto Alegre, a Prefeitura Municipal propôs a criação da Universidade Aberta de Porto Alegre para atuar na desconstrução dos 
projetos vigentes e nas discussões sobre as parcerias público-privadas na educação e na cultura. Vejamos isso a partir de seus programas oficiais de governo.

\section{Proposta de parceria e think tank em Porto Alegre}

Nesta sessão, expomos as discussões sobre as estratégias empregadas pelo governo Nelson Marquezan Junior ${ }^{6}$ (Partido da Social Democracia Brasileira) em Porto Alegre, para divulgação e implementação de propostas de cunho liberal para a gestão municipal, com a desresponsabilização do Estado e com conteúdo e lógica da administração gerencial voltada ao mercado.

De forma breve, apresentamos os documentos oficiais do Programa de Metas de Porto Alegre (Prometas), o Decreto n⿳⼈ㅜㄹ.736, de 2 de maio de 2017, que instituiu o Programa Municipal de Parcerias (Propar/POA), o Plano Plurianual e a proposta divulgada sobre a criação do think tank Universidade Aberta de Porto Alegre (UnA), observando como foram se delineando as propostas de parcerias privadas na gestão pública.

O Prometas 2017/2020,7 segundo a Prefeitura de Porto Alegre, é a oficialização das promessas eleitorais em plataforma de governo, e as metas são definidas como "produtos concretos que a Prefeitura pretende entregar à população ao longo dos próximos quatros anos de gestão" (www.prefpoa.com.br) ${ }^{8}$. O Programa está organizado em três grandes eixos estratégicos: Desenvolvimento Social; Infraestrutura, Economia, Serviços e Sustentabilidade; Gestão e Finanças. Dentro do eixo Desenvolvimento Social, encontram-se a educação, a cultura, a saúde e a proteção social.

Destacamos os objetivos tratados no eixo da Educação. Em relação à universalização da educação infantil, as metas 19 e 20 propõem atender 100\% da demanda de educação infantil para crianças de 0 a 5 anos e 11 meses, sem informar as fontes dos números apresentados.

No objetivo referente à melhoria da qualidade no ensino fundamental, as metas 21 a 27 tratam disso; as duas primeiras metas dizem respeito ao aumento das notas da avaliação obtidas no Índice de Desenvolvimento da Educação Básica (IDEB 2020) nos anos iniciais do ensino fundamental, sem indicar as formas de promover esse crescimento. A meta 23 refere-se também às avaliações e à necessidade de ampliar a proficiência dos alunos nos anos iniciais do ensino fundamental em português e em matemática; as metas 25 e 26 se referem a essa proficiência nos anos finais. A meta 27 vincula o acompanhamento do aprendizado dos alunos a cada semestre pelos descritores da Prova Brasil. Ou seja, a melhoria proposta está centrada na avaliação externa e na aprendizagem em duas áreas do conhecimento, em detrimento das demais; além disso, ficam relegados os investimentos e a valorização no processo de aprendizagem própria de cada sujeito. 
No eixo Gestão e Finanças, o Governo Municipal propõe eficiência na administração pública, e o objetivo indica firmar parcerias estratégicas "com os demais agentes econômicos" (PROMETAS, 2017, p. 60). Compreendemos que já vai-se delineando o interesse da Prefeitura em promover parcerias para atendimento das políticas públicas. Destacamos a meta 51, que define a captação de um bilhão de recursos privados para investimento em obras e serviços públicos não "suportados por recursos do Tesouro Municipal (Idem), e a meta 53 que visa aumentar em 30\% o número de servidores municipais capacitados por meio de "cursos promovidos pela Prefeitura ou parceiros" (Idem, p.62). Esta última meta já está em prática por ações do Governo Municipal com a criação da UnA.

A parceria com o setor privado, para Porto Alegre, respalda-se no Decreto nํㅜ 19.736, de maio de 2017, que instituiu o Programa Municipal de Parcerias (Propar/POA) ${ }^{9}$ e o Conselho Gestor do Programa de Parcerias (CGP), composto por membros do governo municipal (vice-prefeito e secretários municipais). Instituído enquanto órgão superior de caráter normativo e deliberativo, esse programa será responsável pelo planejamento e execução das concessões e parcerias público-privadas no âmbito da administração municipal e, dentre outros, do Plano Municipal de Parcerias Público-Privadas. A constituição majoritária no CGP pelo Executivo implica em decisões monocráticas (uma única posição, um único poder opinando), ignorando os processos democráticos de discussão e decisão na cidade, como as instâncias do Orçamento Participativo ${ }^{10}$ e, ainda que o arranjo dos grupos e comissões temáticas pressuponha a participação e a elaboração de propostas, com a decisão só do CGP. Nas competências do CGP consta "deliberar sobre matérias relacionadas ao Fundo Garantidor de Parcerias Público-Privadas", cuja regulamentação tramita no Congresso Nacional (Projeto de Lei n⿳0 2892/2011). Esse PL propõe a autorização do Fundo a prestar garantias em projetos de parceria e contragarantias dos estados e municípios em igual valor, podendo vincular receitas arrecadadas e provenientes de transferências constitucionais para efetivá-las, direcionando recursos públicos para iniciativa privada.

Outro documento para análise dos projetos municipais é o Plano Plurianual (PPA), instrumento de planificação destinado a atender as demandas de políticas públicas para a população. Segundo a Prefeitura, o PPA foi elaborado com base no Prometas e encaminhado à Câmara Municipal de Porto Alegre sob a responsabilidade da Secretaria Municipal de Planejamento e Gestão em maio deste ano e terá vigência de quatro anos a partir de $2018^{11}$. Destaca o déficit orçamentário do município, reiterando a necessidade das parcerias público-privadas para promover obras de infraestrutura.

No PPA, apesar do discurso de falência do município, foi criada uma nova despesa ${ }^{12}$ para viabilizar o think tank UnA, realizar marketing político e influenciar opiniões. Não se trata de investimento numa política pública que garanta direitos aos cidadãos, mas do pagamento dos parceiros (privados) para realizar as ações. 
Sem um plano de política fiscal que revise as isenções, o governo responsabiliza o funcionalismo público e o investimento em políticas públicas pelo colapso dos serviços e das contas públicas e propõe superar a crise buscando parcerias privadas. Na prática, instituiu o decreto educacional de alteração da rotina escolar (que diminuiu carga horária destinada aos alunos e a merenda distribuída nas escolas, o fim da formação continuada com as reuniões pedagógicas e de planejamento semanais dentro das escolas).

No eixo Gestão e Finanças do PPA, a atual administração afirma que "não se pode governar pensando em interesses corporativos e ideológicos" e que o uso dos recursos públicos tem de ser a favor do cidadão (PPA 2018/2021, p. 12). Entendemos que o planejamento e a execução dos recursos devam ser públicos.

Como já pontuamos na introdução, a prática instituída por meio desses projetos diz respeito a uma estratégia de retirada do Estado da gestão, da execução e do conteúdo da política pública, que passa a ser definida por um grupo de políticos e pensadores voltados a opções que priorizam a regulação via mercado e a gestão gerencial dos espaços públicos. As parcerias público-privadas passam a ser a estratégia principal de governo e buscam formas de legitimar essa proposta.

Destacamos também a relação com os serviços públicos e o funcionalismo que, nesses documentos, são apresentados como responsáveis por grande parte da crise financeira do município e com os quais o governo tem dificuldade de dialogar. Sua estratégia foi criar um think tank (a UnA), para divulgar as ideias que o governo defende, convencer a população e preparar terreno para privatizações e reformas que vem anunciando.

\section{Universidade Aberta de Porto Alegre: Proposta e parceiros}

Porto Alegre notabilizou-se por ter implantado um vigoroso projeto de participação e de decisão da população sobre os rumos da cidade conhecido como Orçamento Participativo, que foi o modo de discutir publicamente os investimentos necessários em cada bairro. No campo educacional, implantou o projeto Escola Cidadã, baseado na promoção da democratização da gestão educacional dentro da escola, na relação com sua comunidade e com a mantenedora. Foram projetos alternativos às propostas neoliberais; possuíam estruturas democráticas, como eleição de diretores, conselhos escolares, Conselho Municipal de Educação, projetos político-pedagógicos em construção e proposta de ensino por ciclos de formação em toda a rede. Mas, desde 2005, esses processos sofrem ataques dos governos, e as escolas resistem ao seu desmonte (BERNARDI, 2016).

A estratégia construída pelo atual prefeito Nelson Marquezan Junior propõe investir no marketing político para questionar tais organizações. Para ele, " a cidade chegou ao caos na infraestrutura, na saúde e na educação, pois perdeu muito tempo com discussões infrutíferas" (www.prefpoa.com.br). ${ }^{13}$ Entre essas estratégias, ele lança a Universidade 
Aberta de Porto Alegre em restaurante de um shopping da cidade com a presença de secretários, de instituições parceiras e da imprensa.

Definida como uma think tank alinhada com modelos internacionais de universidades livres de Paris e centros de pesquisa, formação e advocacy do mundo anglo-saxão (de caráter privado), propõe-se firmar "convênios e acordos de cooperação com outras instituições acadêmicas e instituições nacionais latino-americanas que contribuam para o debate público" (www.prefpoa.com.br).

O projeto Universidade Aberta é coordenado pelas secretarias de Cultura (SMC), de Educação (SMED) e de Desenvolvimento Econômico (SMDE); na aula inaugural, no dia 17 de maio de 2017, ${ }^{14}$ foi acentuado pelo secretário de desenvolvimento econômico, Ricardo Gomes, como fundamental "para o debate de ideias sobre empreendedorismo, formação profissional e cultural para o grande público". Segundo ele, a "finalidade está na construção de uma cultura empreendedora, [...], assim como desestatizar a visão cultural, promovendo a visão de [...] independência do indivíduo [...] para que não dependa do Poder Público", bem ao gosto dos teóricos liberais.

Em entrevista ao jornal O Sul, Ricardo Gomes afirma que a missão da UnA será "contribuir para o debate qualificado de ideias, para a difusão de valores do pluralismo, da liberdade e do empreendedorismo em todas as esferas da vida pública" ( $\mathrm{O}$ SUL,15/05/2017, capa).

Para o idealizador da UnA, o secretário adjunto da Cultura, Ricardo Wolf, ela "será uma ferramenta extremamente importante, pois permitirá uma virada de mentalidade: romper com a estreiteza ideológica que tomou conta do debate público" (OSUL, 15/05/2017, capa), cujo slogan é: "Ideias têm consequências ${ }^{15}$." A iniciativa, segundo este secretário, tem o objetivo de "superar as fragilidades de ações isoladas e sem continuidade pela incapacidade de conexão de pessoas e instituição" (CORREIO DO POVO, 27/07/2017, capa.)

Para a educação, a interface está na formação continuada dos professores da Rede Municipal de Ensino. Segundo Wolf, "Espero que esse venha a ser mais do que um programa de ações, mas que se institucionalize como um programa contínuo de capacitação técnica, pessoal e profissional" (O SUL, 15/05/2017, capa).

Se analisarmos o conceito-chave da UnA, podemos entender o alinhamento a que se propõe a política. Na sociedade, na administração, como nos estudos acadêmicos, uma das formas de atuação do Terceiro Setor, que vem se destacando, é o papel de influenciar políticas públicas, também conhecido por advocacy. Segundo Gabriela de Brelàz,

O papel de advocacy é vital para as organizações do terceiro setor e é uma função muito tradicional nos Estados Unidos onde cidadãos sempre se associaram através das organizações da sociedade civil e contribuíram para moldar as características políticas, econômicas e culturais do país [...] Por advocacy entendemos o ato de identificar, adotar e promover uma causa. É um esforço para moldar a percepção pública ou conseguir alguma mudança (BRELÀZ, 200716). 
Alguns autores denominam de advocacy think tanks (ROCHA, 2015, p. 265); aqui entendemos tratar-se da mesma proposta e, ao observar a criação do think tank da Universidade Aberta de Porto Alegre, podemos aludir que foi cunhado para influenciar o clima político, promovendo a naturalização dos discursos sobre as parcerias públicoprivadas na cultura e na educação.

Ao olhar os sujeitos da Universidade Aberta, deparamo-nos com uma clara opção por parceiros e instituições liberais defensoras da ampliação do privado no setor público. Vejamos na figura abaixo quem são os idealizadores e parceiros desta think tank:

\section{Figura 1 - Os sujeitos da uma}

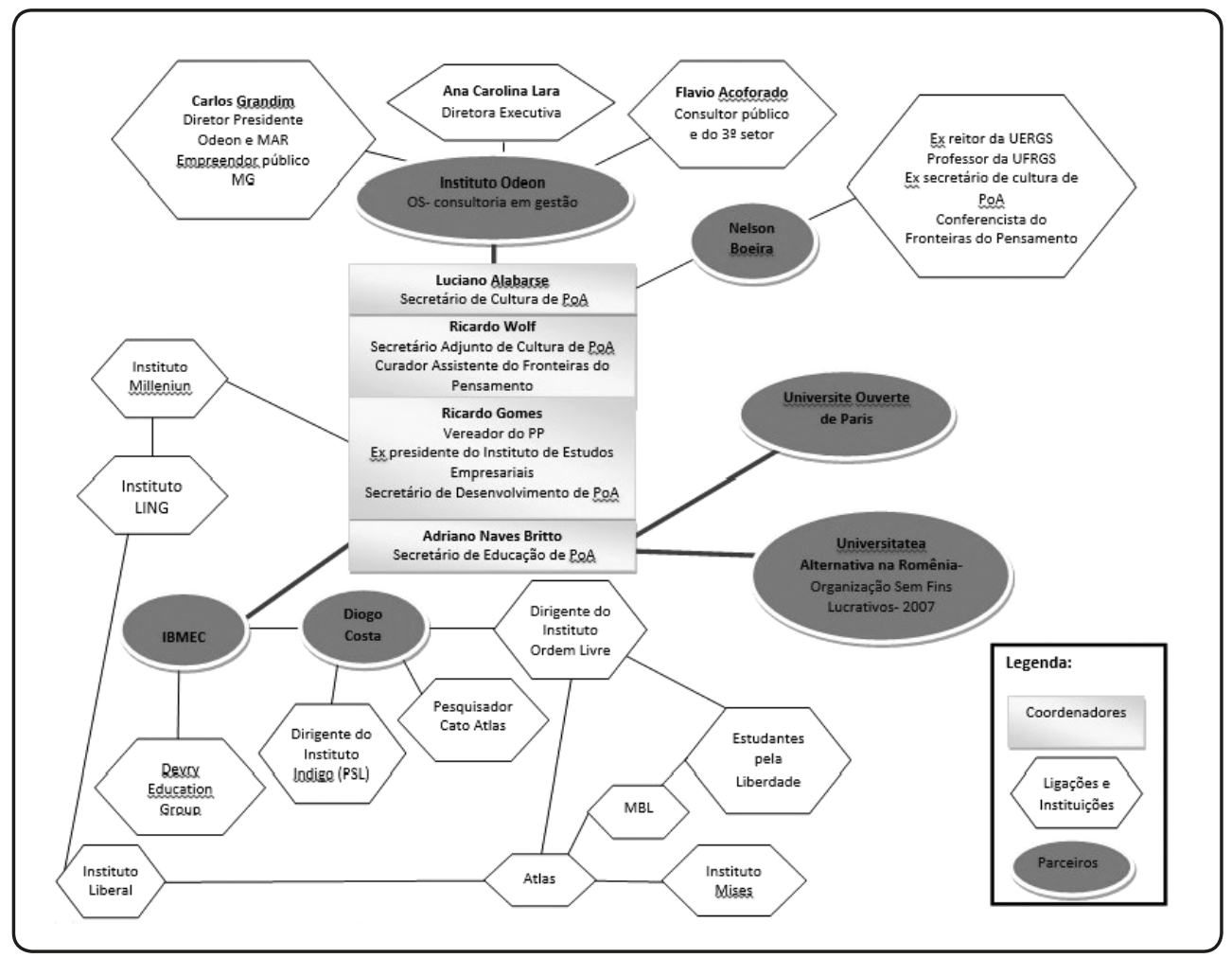

Fonte: Elaborada pelos autores a partir dos sites da Prefeitura e jornais)

Os apoiadores da UnA são os mesmos think tanks liberais (Instituto Liberal, Instituto de Estudos Empresariais, MBL, Cato, Atlas, Millenium...) que apresentamos no histórico inicial, comprovando sua ação de promotores de ideias e conteúdos de políticas. Também ressaltamos o Ibmec, uma instituição privada de ensino, cujo representante junto à UnA - Diogo Costa - é pesquisador do Cato e do Atlas. Entendemos que fica demarcada qual a opção societária desta proposta para Porto Alegre. 
A Prefeitura retirou estruturas participativas da cidade e ofertou o think tank de cunho liberal, ampliando o espaço da ação para as parcerias privadas interferirem no setor público. Entendemos que isso encolhe a democratização da educação, pois reduz as possibilidades de debate e, contraditoriamente, oferece um novo espaço, com diálogo e direção já definidos.

\section{Considerações finais}

Neste artigo apresentamos as organizações liberais formadoras de opinião, conhecidas como think tanks, que proliferam no Mundo e no País, atuando sobre assuntos estratégicos na construção de consenso para a elaboração de políticas públicas como elementos centrais de fazer política (MORAES, 2015).

Criados pelos norte-americanos, os think tanks logo se constituíram com ação radical na defesa do livre mercado e do empreendedorismo. Destacamos como mais influentes e conhecidos no Brasil, o Heritage Foundation, o Atlas Foundation e o Cato Institute. Todas essas instituições, com milhões de dólares de orçamento, agem na defesa da reestruturação produtiva do capitalismo e na necessidade de uma nova subjetividade neoliberal, competitiva, empreendedora e individualista.

No Brasil, patrocinaram a organização de institutos como o Liberal, o de Estudos Empresariais, nos anos de 1980 e em 2000; essas organizações se multiplicaram com o Instituto Millenium, o Instituto Ordem Livre, O Movimento Brasil Livre etc., atuando em defesa da liberdade do livre mercado.

Em Porto Alegre, o atual prefeito criou um think tank com ênfase no empreendedorismo para atuar nos setores da cultura (cedendo espaços públicos à iniciativa privada) e na educação (na formação de professores municipais, ao mesmo tempo em que alterou rotinas na escola e acabou com as reuniões de discussão, planejamento e formação).

Apoiada por instituições liberais e nos moldes de universidades abertas, os parceiros da UnA são reconhecidos ativistas em instituições ligadas aos think tanks americanos e brasileiros de direita como Atlas, Milleniun, Estudantes pela Liberdade, MBL, Ordem Livre, Mises etc.

As propostas de ação da UnA demonstram a intencionalidade de questionar conceitos e políticas progressistas, como a estrutura do Orçamento Participativo, os princípios da Escola Cidadã, as organizações sindicais (com ataques ao funcionalismo, entre outros) e, ao mesmo tempo, de promover programas liberais, ampliando as parcerias públicoprivadas, ou seja, a sociedade civil devendo buscar sucesso no mercado.

Em tempos de destruição de pessoas e bandeiras que defendem políticas sociais universais e estatais, precisamos estar atentos a esses movimentos, que articulam novas 


\section{formas de propor o velho arcabouço liberal. Necessitamos defender cultura e educação como direito e, ao tratar a coisa pública, que a gestão seja pública e democrática.}

\section{Recebido em 29/09/2017 e aprovado em 15/11/2017}

\section{Notas}

1 Sobre essa base teórica, ressaltamos que o novo liberalismo se assentou em três grandes escolas do pensamento influenciados por Ludwig Von Mises : a) Escola Austríaca, liderada por Friedrich Von Hayek, que lançou os fundamentos da economia de mercado; b) Escola de Virgínia ou Public choice, liderada por James Buchanan, que defendeu a escolha pública como forma de reconciliar interesses de classes conflitantes; c) Escola de Chicago, com Milton Friedman, Theodore Schultz e Gari Becker.

2 A escola de Chicago treinou economistas do governo Pinochet, no Chile: os "Chicago Boys".

3 Hayek, em "O caminho da servidão", critica o Estado de bem-estar social.

4 Também conhecido como Atlas Network.

5 http://www.esquerdadiario.com.br/O-que-se-esconde-por-tras-do-Movimento-Brasil-Livre(MBL)

6 Seu mandato se estende de $01 / 01 / 2017$ a 31/12/2020.

7 O Prometas foi incluído à Lei Orgânica, por meio da Emenda n 36/2015, e a partir daí o prefeito tem um prazo de noventa dias para apresentar o Plano Plurianual, com metas, fontes e os recursos para a sua operacionalização.

8 Site consultado em 24/06/2017.

9 Esse decreto revogou os Decretos nº 15.370/ 2006, e nº 15.448/2007.

10 Essa política foi implantada durante os anos de 1989 e 2004 quando o município foi administrado pela administração popular, tendo a frente o Partido dos Trabalhadores.

11 http://lproweb.procempa.com.br/pmpa/prefpoa/smpeo/usu_doc/ppa_2018-2021.compressed.pdf- PPA acessado em 06/06/2017

12 No total R\$ 896.627,00.

13 Consulta ao site em 15.05.2017.

14 Palestra proferida no dia 17 de maio na Casa dos Conselhos/POA.

15 Frase atribuída a Richard Weaver, em 1948, que se tornou um refrão do pensamento conservador pós Segunda Guerra Mundial.

16 Disponível em <www.anpad.org.br/admin/pdf/APS-A1916.pdf> Acesso em 22.09.2017. 


\section{Referências}

BEHRING, Elaine Rossetti. Brasil em contra-reforma: desestruturação do estado e perda de direitos. São Paulo: Cortez, 2008.

BERNARDI, Liane Maria. Implicações do Plano de Ações Articuladas na democratização da gestão da educação. Tese de Doutorado. Porto Alegre, UFRGS, 2016.

BRELÁZ. Gabriela. Advocacy das Organizações da Sociedade Civil: Principais Descobertas de um Estudo Comparativo entre Brasil e Estados Unidos. XXXI Encontro da ANPAD. Rio de Janeiro, 22 a 26 de setembro de 2007.

DARDOT, Pierre; LAVAL, Christian. A nova razão do mundo: ensaio sobre a sociedade neoliberal. São Paulo: Boitempo, 2016.

PMPA. DECRETO № 19.736, DE 2 DE MAIO DE 2017.

GIDDENS, Anthony. A Terceira Via: reflexões sobre o impasse político atual e o futuro da social democracia. Rio de Janeiro: Record, 2001.

MORAES, Reginaldo. Neoliberalismo: de onde vem, para onde vai? São Paulo: Senac, 2001.

A organização das células neoconcervadoras de agptrop: o fator subjetivo e a contrarrevolução. In: JINKINGS, Ivana; DORIA, Kim; CLETO, Murilo (Org). Por que gritamos Golpe? Para entender o impeachment e a crise política no Brasil. São Paulo: Boitempo, 2015.

PMPA.PARCERIAS PÚBLICO-PRIVADAS Lei № - 11.079, de 30 de dezembro de 2004.

PREFEITURA MUNICIPAL DE PORTO ALEGRE. Programa de Metas 2017/2020.

PERONI, Vera; ADRIÃO, Theresa (orgs). Público não estatal: Estratégias para o setor educacional brasileiro. In: O público e o privado na educação: interfaces entre Estado e sociedade. São Paulo: Xamã, 2005.

Implicações da relação público privada para a democratização da gestão. Tese de professor titular da Carreira de Magistério Superior UFRGS. Porto Alegre, 2015.

ROCHA, Camila. Direitas em rede: Think tanks de direita na América Latina. In: JINKINGS, Ivana; DORIA, Kim; CLETO, Murilo (Org). Por que gritamos Golpe? Para entender o impeachment e a crise política no Brasil. São Paulo: Boitempo, 2015.

\section{Sites:}

$<$ http://www2.camara.leg.br/camaranoticias/noticias/> site acessado em 03/06/2017

Câmara dos Deputados, Projetos de Leis e outras Proposições,

<http://www.camarapoa.rs.gov.br/> Plano Plurianual 2018/2021. Acessado em 06/06/2017.

$<$ http://portal.tcu.gov.br/comunidades/administracao-e-encargos-especiais/inicio/> Acessado em 22/06/2017. 
$<$ http://www.prefeituramunicipaldeportoalegre.gov.br> Acessado em 15.05.2017. <http://www2. portoalegre.rs.gov.br/smed/default.php?p_noticia> Acessado em 15.05.2017

$<$ http://www2.portoalegre.rs.gov.br/portal_pmpa_novo/> Acessado em 17.05.2017 